\title{
Relato de Experiência na Educação Especial em Engenharia de Software com um Sistema Tutor Inteligente
}

\author{
Laércio Silva de Sousa Júnior, Emanuel Holanda Barroso, \\ Vandor Roberto Vilardi Rissoli
}

\author{
Engenharia de Software \\ Universidade de Brasília - Faculdade do Gama \\ Apoio: Conselho Nacional de Desenvolvimento Científico e Tecnológico (CNPq) \\ laerciossjregmail.com, manusenac@hotmail.com, vandorissoli@gmail.com
}

\begin{abstract}
This article had the objective to express successful results in the tutorial work involving a student with special needs, a classmate as tutor and some software used in the personalized monitoring of these students. The results of this work reflect the development in the learning of the special student, the tutor student, as well as in the success of the adopted methodology that resulted in the approval of these students in the discipline of Objects Orientation of the course of Software Engineering.
\end{abstract}

Resumo. Este artigo tem como objetivo expressar os resultados de sucesso no trabalho de tutoria envolvendo um aluno com necessidades especiais, um colega de turma como tutor e alguns softwares empregados no acompanhamento personalizado desses alunos. Os resultados deste trabalho refletem o desenvolvimento na aprendizagem do aluno com deficiência, do aluno tutor, bem como no êxito da metodologia adotada que resultou na aprovação desses alunos na disciplina de Orientação a Objetos, do curso de Engenharia de Software.

\section{Introdução}

As pessoas são diferentes em vários aspectos que podem ser analisados. Entretanto, existem pessoas que precisam de atenção e cuidados necessários para superar barreiras de dificuldades locomotoras, auditivas, visuais ou de desenvolvimento neurológico ou psicológico. Alunos com deficiência são pessoas que, por algum motivo em seu desenvolvimento, precisam de certas adequações adicionais no programa educacional para a sua plena progressão intelectual, assim como, em sua possível autonomia e independência (Veneziano et al, 2016).

É garantido por lei no Brasil que alunos com deficiência tenham um ensino diferenciado por conta de sua necessidade. Porém, também é preciso que esse processo educacional não faça com que tais alunos se tornem dependentes. É necessário que seu educador conheça diferentes metodologias e ferramentas tecnológicas que propiciem o desempenho adequado à aprendizagem e independência possível desses alunos.

A Política Nacional de Educação Especial no Brasil trabalha na perspectiva da educação inclusiva, tendo esta inclusão um amplo desenvolvimento apoiado por tecnologias que facilitam o processo educacional especial, além do acompanhamento personalizado da situação de aprendizagem de cada estudante (Santos, 2010). Atualmente, a maioria dessas tecnologias se tornou acessível à grande parte da população 
VIII Congresso Brasileiro de Informática na Educação (CBIE 2019)

Anais do XXV Workshop de Informática na Escola (WIE 2019)

pelo baixo custo, propiciando, a milhões de brasileiros com deficiência, um ensinoaprendizagem mais adequado, em que algumas instituições ainda empregam softwares educacionais "inteligentes" no acompanhamento de seus alunos (Melo et al, 2012).

Entre estes softwares educacionais têm-se destacado os Sistemas Tutores Inteligentes (STI), que integram metodologias educacionais coerentes com o suporte tecnológico adequado aos seus objetivos letivos. No entanto, poucos são os STI que implementam recursos de acessibilidade aos alunos com deficiência.

Este trabalho está dividido em mais três seções e apresenta as principais ações de apoio ao sucesso na aprendizagem de um aluno com deficiências no curso de Engenharia de Software, na disciplina de Orientação a Objetos, e de seu colega de turma e tutor dedicado ao auxílio condizente com as necessidades de melhor esclarecimento e atenção ao aluno deficiente. A seção 2 mostra a situação existente e os recursos empregados, enquanto a seção 3 apresenta alguns dos resultados observados para as conclusões abordadas na seção 4 deste artigo. As principais referências encerram este trabalho.

\section{Apoio à Educação Especial}

A constituição brasileira garante o desenvolvimento pleno dos cidadãos, sem preconceito de origem, raça, sexo, cor, idade ou quaisquer outras formas de discriminação. Porém, a ação mais acolhedora e de respeito com as diferenças existentes entre cada ser humano é voluntária e depende de pessoas que desejam ajudar o outro a partir de sua própria compreensão e disposição ao possível auxílio.

Nos processos educacionais as diferenças podem ser marcantes para a realidade de cada aluno deficiente, que, geralmente, precisa de maior compreensão e acolhimento diferenciado para as suas possíveis superações. Embora a legislação brasileira se apresente comprometida com os aspectos da inclusão, as ações condizentes com a estimativa de pessoas com algum tipo de deficiência não atendem as suas necessidades, inclusive no âmbito escolar (Santos, 2010).

Assim, as instituições educacionais têm promovido programas de amparo e orientação aos profissionais de educação e ao acolhimento especializado dos discentes. Recursos tecnológicos têm sido empregados no apoio à atuação desses profissionais, a fim de colaborarem com o ensino e a aprendizagem, possibilitando um processo educacional melhor acompanhado por ser personalizado com as características dos alunos.

Diante desta realidade, esse trabalho vem compartilhar um caso de sucesso ocorrido em uma universidade federal brasileira que empregou tecnologias de assistência aos diferentes perfis de participantes envolvidos com o ensino-aprendizagem. Essa instituição federal possui o Programa de Apoio às Pessoas com Necessidades Especiais (PPNE) que visa atender alunos com deficiências físicas, mentais, com déficit de atenção e hiperatividade (TDAH), além de orientar os profissionais de educação que estarão trabalhando com esses alunos. O PPNE objetiva proporcionar o livre exercício da cidadania, existindo várias ações propostas por este programa, sendo destacado neste artigo o Programa de Tutoria Especial (PTE) (PPNE, 2019).

Os envolvidos no PTE são um ou mais estudantes que estão cursando a mesma disciplina/turma que o aluno com deficiência, sendo estes estudantes reconhecidos como tutores do aluno deficiente. Desta forma, o tutor tem uma integração contínua com esse aluno no período de aula (na sala de aula) e em atividades extraclasse. Essa integração 
VIII Congresso Brasileiro de Informática na Educação (CBIE 2019)

Anais do XXV Workshop de Informática na Escola (WIE 2019)

visa estabelecer a interação entre os aprendizes, promovendo uma melhora na compreensão do conteúdo disciplinar, em que o docente orienta o tutor, de acordo com o acompanhamento da situação de aprendizagem do aluno deficiente e do próprio tutor.

No entanto, uma proposta inovadora foi realizada durante um semestre letivo envolvendo um aluno com deficiências associado ao PTE que obteve o auxílio de um tutor humano e outro virtual, correspondendo este último a um STI (Rissoli e Santos, 2011).

\subsection{Características do ambiente educacional envolvido}

O PPNE reconheceu a presença de múltiplas deficiências (TDAH, física, auditiva e apneia do sono decorrente de Hidrocefalia) no aluno de 20 anos de idade, que estava matriculado na disciplina de Orientação a Objetos (OO) oferecida pelo curso de graduação em Engenharia de Software.

Esse reconhecimento aconteceu mediante a apresentação de documentos e exames médicos, além da interação direta com os profissionais do PPNE. As deficiências confirmadas pela equipe do programa estão na Classificação Estatística Internacional de Doenças e Problemas Relacionados com a Saúde (CID) como F41-2 (transtorno misto ansioso e depressivo) e F60 (transtornos específicos de personalidade) (Caetano, 1993).

Assim, o PPNE iniciou suas atividades de assistência ao coordenador do curso e ao docente da disciplina, inclusive sobre o processo de seleção e orientação do estudante que se tornaria o tutor humano do aluno com deficiência. Todos estes perfis (coordenador, professor e tutor) trabalhariam sintonizados aos objetivos da disciplina, atuando de maneira pertinente com as características diagnosticadas no aluno deficiente para que seu acolhimento fosse fraterno e adequado em sua inclusão social na turma de OO.

A disciplina de OO objetiva a aprendizagem prática de um paradigma da área de Programação Computacional (Scoot, 2005). Essa área é reconhecida como uma das mais difíceis na formação dos cursos de Informática, pois envolve o emprego de conhecimentos lógicos e habilidades intelectuais para construção de uma solução pertinente aos problemas existentes na área da Programação (Delgado et al, 2004).

Consciente dessa realidade o docente elaborou uma estratégia didáticopedagógica que envolvia o aluno tutor interagindo de forma contínua e ativa com o aluno com deficiência, empregando recursos tecnológicos para estabelecer esta interação presencial e a distância. Assim, o tutor se encontraria, presencialmente, com o aluno deficiente pelo menos uma vez por semana, e quantas fossem necessárias em meio virtual, por exemplo, na interação por e-mail, através de chat ou fórum, além do controle assumido pelo tutor do computador do aluno com deficiência a distância, em ocasiões peculiares ao esclarecimento necessário, por meio do software TightVNC (2019).

\subsection{Metodologias educacionais}

A postura educacional do docente dessa turma de $\mathrm{OO}$ foi baseada em alguns pressupostos da Teoria da Aprendizagem Significativa (TAS) e em alguns postulados provenientes das Metodologias Ativas, a fim de promover um processo educacional contínuo e assistido por tecnologias interativas que propiciem o "aprender fazendo", assim como o "fazer aprendendo" (Gomes et al, 2010).

Respeitando os postulados da TAS, que entendem que o desenvolvimento humano mais natural deve partir das ideias mais gerais e inclusivas (Diferenciação Progressiva) 
VIII Congresso Brasileiro de Informática na Educação (CBIE 2019)

Anais do XXV Workshop de Informática na Escola (WIE 2019)

para depois progredir explorando as especificidades relevantes desse novo conteúdo assimilado, efetuando, de maneira inversa ao pressuposto inicial e mais natural, a apreensão cognitiva dos detalhes similares ou discrepantes que serão integrados a essas ideias mais gerais (Reconciliação Integrativa). Esse processo de associação do novo conteúdo ao conhecimento já estabelecido na estrutura mental do aprendiz (subsução) é fundamental à aprendizagem se tornar significativa (Ausubel, Novak e Hanesian, 1980).

O uso de tecnologias condizentes para a realização desse processo educacional é relevante, principalmente, para o acompanhamento personalizado da situação de aprendizagem dos estudantes, sendo utilizado um STI para estimular a interação coerente a fim de suprir as possíveis dificuldades de cada aprendiz (Rissoli e Santos, 2011).

\subsection{Tecnologias de apoio}

As pesquisas que procuravam softwares educacionais que pudessem ser empregados como recurso de apoio ao ensino de $\mathrm{OO}$, com a participação do aluno com deficiência e seu tutor, encontraram uma quantidade de recursos de acessibilidade expressiva. No âmbito dos Sistemas de Conhecimento alguns softwares também foram analisados, sendo destacada a proposta do STI de Azevedo e Tavares (2018), além do Sistema Especialista (SE) de Omar, Fonseca e Pasotto (2004).

Apesar de interessantes, nenhum dos softwares pesquisados fornecia recursos integrados de maneira satisfatória aos objetivos dessa turma, mas poderia ser formado um "coquetel" de softwares no fornecimento desse apoio, em que o STI, de Azevedo e Tavares, trabalharia os conceitos de OO, enquanto o SE se preocuparia com o ensino da linguagem Java. Contudo, este STI só possuía o aprendiz como usuário, não fornecendo subsídios ao docente ou ao tutor, conforme fossem ocorrendo interações do aluno com deficiência. O SE para Java também não compartilhava os dados de acompanhamento com os demais participantes do processo educacional, além de não promover atividades condizentes com o aprofundamento prático do paradigma de programação estudado.

Porém, alguns STI mais modernos, que incluem o docente como usuário e participante influente do processo, foram pesquisados, mas os seus conteúdos letivos eram específicos e não envolviam a OO. Aqueles que envolviam eram limitados ao aprendiz e no máximo ao docente, não fornecendo nenhum recurso de acessibilidade desejado e nem suporte para a atuação do aluno tutor.

Diante dessas opções restritivas, o STI conhecido como SAE (Sistema de Apoio Educacional) surgiu como a melhor alternativa por construir um repositório único de acompanhamento da situação dos alunos e em utilizar este repositório como recurso de assistência para as interações dos diferentes perfis (aluno deficiente, tutor, professor e coordenador do curso) que participariam desse processo educacional. A comunicação interativa sempre disponível pelo chat do SAE aos seus usuários e a orientação fornecida por seu agente pedagógico animado, com recomendações ativas aos discentes, também contribuíram na definição do SAE como um dos softwares educacionais empregados na superação dos desafios existentes nesta turma de OO, sendo ainda relevante a fundamentação pedagógica desse STI baseada na TAS (Rissoli e Santos, 2013).

A linguagem de programação Java foi escolhida para o estudo da $\mathrm{OO}$, enquanto que o Ambiente Virtual de Aprendizagem (AVA) MOODLE foi adotado como recurso responsável pela gestão dos conteúdos de estudo, interação dentro e fora de sala de aula 
(fóruns e chats), além do compartilhamento de materiais instrutivos e de soluções de problemas propostos pelo professor e resolvidos através de programas de computador.

Assim, o amparo tecnológico possibilitava interação contínua em período extraclasse e o apoio letivo sobre cada um dos conteúdos que formavam a disciplina de OO. Orientações pedagógicas condizentes ao momento de estudo do tutor e do aluno deficiente eram fornecidas pelo agente pedagógico do SAE, denominado MInA, respeitando a agenda de estudo de cada aprendiz e se mantendo sintonizado com a realidade cognitiva inferida por este STI que emprega Lógica Fuzzy em suas análises (Rissoli e Santos, 2011).

Os diferentes módulos arquiteturais do SAE ainda ofereciam assistência pertinente para as necessidades de cada perfil participante desse processo educacional, permitindo um acompanhamento ainda pormenorizado do tutor e do aluno deficiente.

O uso do agente MInA na interação com os alunos envolvia aspectos emotivos no processo de orientação para a aprendizagem, procurando ainda motivar os alunos na superação de dificuldades em seus horários disponíveis ao estudo. A Figura 1 ilustra a arquitetura modular do SAE e destaca seus diferentes módulos em relação a arquitetura mais tradicional dos STI, além de identificar os seus perfis de usuários (Rissoli e Santos, 2013).

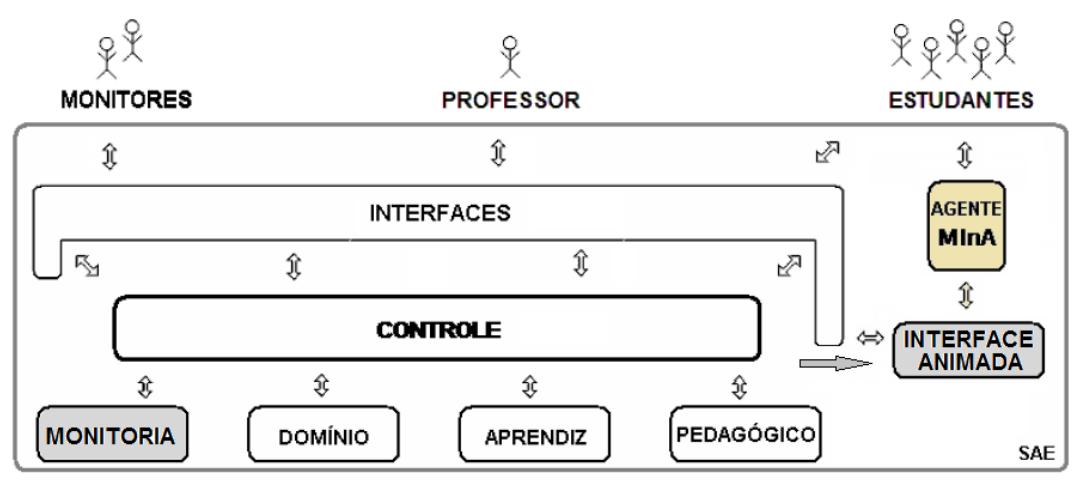

Figura 1. Arquitetura do Sistema Tutor Inteligente SAE com módulos Monitoria e MInA.

Os módulos Domínio (conteúdo letivo), Aprendiz (modelagem de aluno) e Pedagógico (diretrizes metodológicas) mantêm suas características funcionais aos STI mais tradicionais, sendo expandidos suas ações com a integração do módulo Monitoria e MInA (Módulo de Interface Animado) na arquitetura do SAE. Estes novos módulos possibilitam maior captação de dados provenientes do processo educacional e fornecem novas interfaces à interação com uma gama maior de diferentes perfis de usuários.

A atividade do aluno tutor também pode ser registrada no SAE, por meio do módulo Monitoria, independente dela ter acontecido a distância ou presencialmente. A interação a distância poderia acontecer por meio dos fóruns promovidos pelo docente e que possibilitavam a interação do tutor com o aluno deficiente pelo AVA. A comunicação síncrona entre ambos também poderia acontecer pelo chat disponível no SAE desde o início das atividades letivas dessa turma.

O software Tight $\mathrm{VNC}$ também foi usado na interação a distância entre o tutor e o aluno com deficiência, principalmente, onde a ação mais invasiva sobre o computador do aluno era necessária. Esse software consiste em um pacote gratuito para se estabelecer um controle sobre o computador que está distante. Assim, pode-se observar a área de trabalho do outro computador remotamente e até controlá-lo pelo mouse e pelo teclado local, como se a pessoa distante estivesse em frente ao próprio computador remoto. 
VIII Congresso Brasileiro de Informática na Educação (CBIE 2019)

Anais do XXV Workshop de Informática na Escola (WIE 2019)

As possíveis ações ou orientações realizadas pelo tutor, usando o Tight $\mathrm{VNC}$, eram também registradas no SAE pelo próprio tutor, por meio dos recursos do módulo Monitoria. Assim, o SAE obtinha ainda mais informações sobre o esforço e o desempenho do aluno deficiente, enriquecendo sua assistência ao docente e ao próprio tutor, bem como poderia fornecer orientações pedagógicas mais condizentes com o estado cognitivo desse aluno. Essas orientações continham recomendações ativas de como o aluno ainda poderia melhorar sua assimilação. A Figura 2 mostra uma janela de orientação da MInA ao aluno.

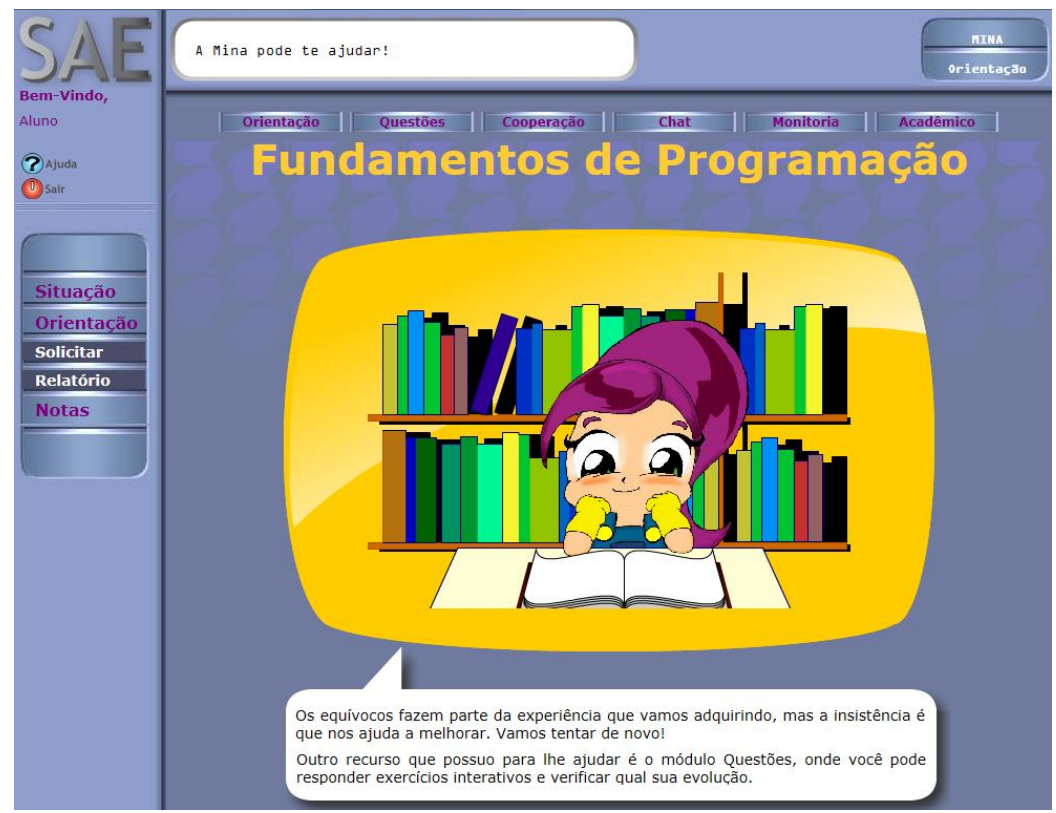

Figura 2. Tela interativa do SAE onde o agente MInA fornece orientação direta ao aluno.

É importante salientar que o processo de "aprendizagem" do software SAE (aprendizagem de máquina) sobre a organização dos conteúdos envolvidos em uma disciplina está relacionado com a elaboração do Mapa Conceitual dessa disciplina. Esse mapa corresponde a uma técnica associada a TAS que representa a organização hierárquica entre os conceitos que serão explorados pela disciplina (Moreira, 2010).

A partir desse mapa, e de alguns metadados relevantes ao acompanhamento do SAE, o potencial da inferência sobre a situação de aprendizagem de cada estudante por este STI é ampliado, combinando alguns desses metadados aos princípios da Diferenciação Progressiva e da Reconciliação Integrativa da TAS para promover o processo de subsunção de novos conteúdos na estrutura cognitiva dos aprendizes.

A quantidade maior de fornecimento de metadados usados pelo SAE, em consonância com a experiência do docente da turma, e ajustados aos objetivos da disciplina, promoverá o aumento no potencial de discriminação desse STI, subsidiando seu processo de inferência fuzzy que acompanha o comportamento de cada estudante, analisando dados quantitativos e qualitativos por meio das variáveis linguísticas esforço, desempenho e participação. Os esclarecimentos relacionados a apuração dessas variáveis e a inferência realizada pelo SAE não estão no escopo desse artigo, mas podem ser verificadas nos relatos de Rissoli e Santos (2011) em profundidade.

A combinação dessas tecnologias no apoio ao processo educacional almejado para OO atendia aos métodos desejados por seu professor e colaborariam com os dois principais estudantes observados neste artigo (aluno com deficiência e tutor), fornecendo- 
VIII Congresso Brasileiro de Informática na Educação (CBIE 2019)

Anais do XXV Workshop de Informática na Escola (WIE 2019)

lhes atividades contínuas no horário e no ritmo adequado de cada um deles, assim como na orientação pedagógica que poderia ser obtida do SAE a qualquer momento que fosse possível o estudo desses estudantes (juntos ou individualmente) com acesso à Internet.

É importante ressaltar que a tecnologia AVA e o SAE foram utilizados por toda turma de OO (23 alunos), a fim de se estabelecer um processo educacional personalizado e de qualidade aos alunos da disciplina, além de efetivar a inclusão do aluno deficiente.

No entanto, a tutoria dedicada e respaldada pelo PPNE só estava acontecendo para o aluno com deficiência, em que um acompanhamento mais intensivo ao trabalho contínuo de motivação e esclarecimentos condizentes aos conteúdos de maiores dificuldades desse aluno eram prontamente atendidos e reforçados por uma postura ativa do tutor e dirigida pelo professor, a fim colaborar mais com a efetivação do processo de subsunção durante a aprendizagem desses dois estudantes (aluno deficiente e tutor).

\section{Resultados}

As decisões docentes de organização da disciplina de OO podem ser observadas por meio dos dados que indicam a condução ativa e participativa de todos os envolvidos. Como pode ser notado na Figura 3, o volume de questões resolvidas por todos os alunos da turma foi expressivo, além das solicitações de orientações para o agente MInA.

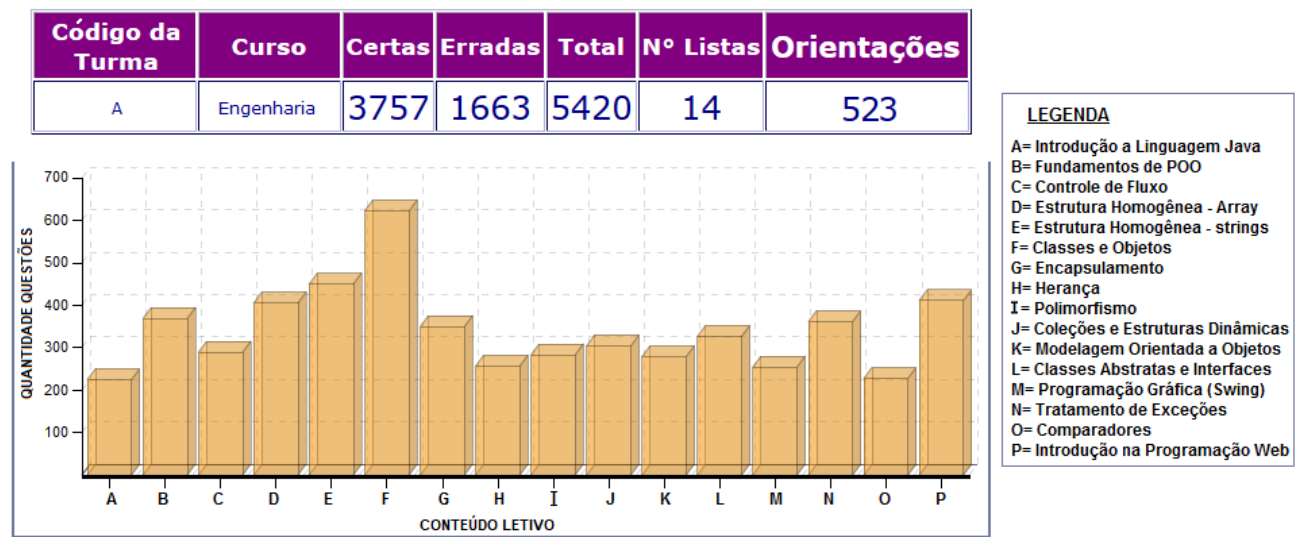

Figura 3. Composição de janelas do SAE indicando a quantidade de questões resolvidas no semestre e distribuídas por cada conteúdo letivo de 00.

Com base na informação fornecida pelo docente, de que todas as suas listas de exercício só possuíam 10 questões cada uma, e partindo da hipótese de que todos os alunos da turma realizaram essas 14 listas solicitadas pelo docente, 3220 questões teriam sido resolvidas através de listas $(59,4 \%)$, enquanto que 2200 (40,6\% das 5420 indicadas na Figura 3) teriam sido resolvidas de maneira avulsa (sem solicitação do docente) pelos alunos que estavam procurando aprender, de forma mais autônoma, a fim de atingir o nível de aprendizado mínimo para as expectativas do SAE, definidas pelo docente de OO.

A Figura 4 mostra estes dados particularizados ao aluno deficiente e ao tutor, apresentando o empenho de cada um para tornar sua própria aprendizagem satisfatória aos objetivos da disciplina. É possível notar que ambos solicitaram mais orientações ao agente MInA que a média aritmética de todas as orientações solicitadas pelos 23 alunos da turma de OO (média de quase 23 por aluno). De acordo com a Figura 4, o aluno com deficiência fez 32 solicitações de orientação, enquanto o tutor fez 35. Porém, o esforço de ambos foi diferente, estando numa escola de 30 para o tutor e de 60 para o aluno. 
VIII Congresso Brasileiro de Informática na Educação (CBIE 2019)

Anais do XXV Workshop de Informática na Escola (WIE 2019)

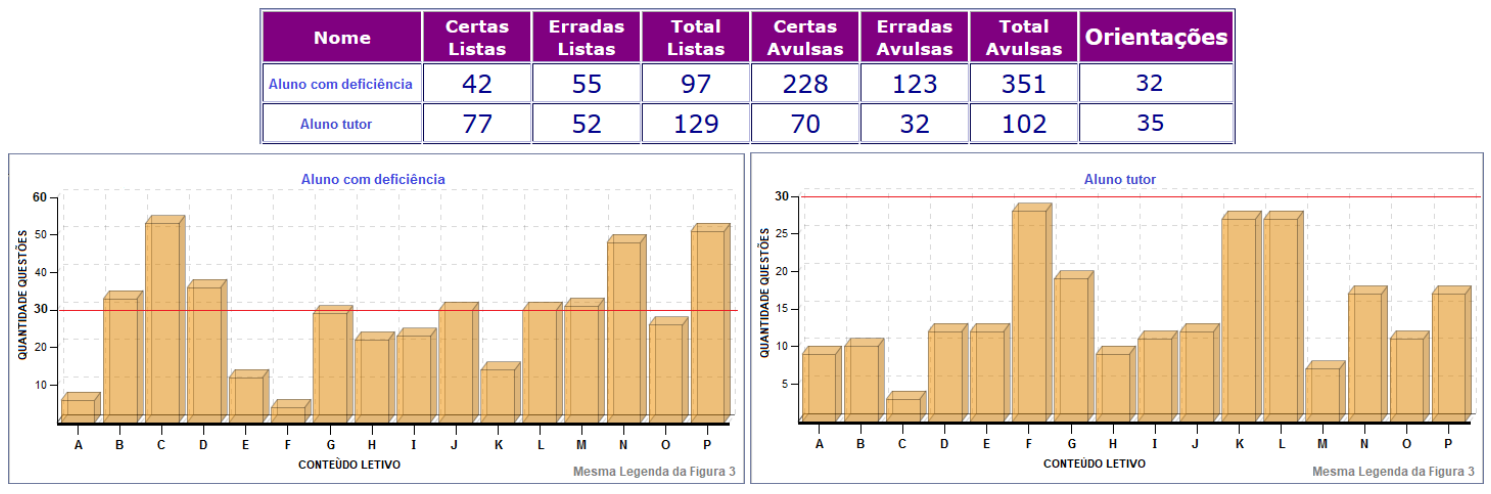

Figura 4. Composição de telas do SAE mostrando a quantidade de questões resolvidas em escalas diferentes e de orientações solicitadas pelo aluno deficiente e pelo tutor.

O esforço de cada um pode ser verificado pela comparação do volume de questões resolvidas, em que a média para a turma seria de 235 questões por aluno, tendo o tutor resolvido 231 questões entre as listas e as avulsas, enquanto que o aluno deficiente resolveu 448. É possível examinar a diferença na necessidade de maior esforço do aluno com deficiência e do tutor em cada item do conteúdo letivo de OO comparando os gráficos de barra da Figura 4. Nessa comparação se pode observar os conceitos estudados que cada um desses estudantes teve maior dificuldade, pois indicam o esforço empregado por eles para alcançar a situação de aprendizagem satisfatória na análise realizada pela MInA. Também é possível notar que a realidade do aluno tutor está mais sintonizada com a realidade da turma, quando comparado o seu gráfico da Figura 4 com o gráfico da Figura 3.

Esse tipo de observação permite verificar a situação de aprendizagem de cada discente em tempo real, no qual a ação do docente pode ser realizada de forma condizente com a estratégia que fosse mais adequada para a realidade de cada aprendiz. O detalhamento de cada orientação fornecida aos aprendizes, assim como de cada questão respondida, pode ser acessada pelo tutor, coordenador do curso e pelo professor. Detalhes da solução como o tempo de resposta para cada questão, o nível de dificuldade e o tipo de questão respondida podem ser comparados com os de outros estudantes, também podendo ser averiguados pelo docente com rapidez e a qualquer momento durante o período letivo.

É interessante ainda observar que a interação entre os principais envolvidos neste processo educacional proporcionou a compreensão da turma em relação as participações e dificuldades do aluno com deficiência durante a disciplina, além de propiciar a primeira experiência acadêmica ao aluno tutor, como mediador de um processo educacional.

$\mathrm{O}$ respeito a alguns dos princípios da TAS e ao método intuitivo proposto por Pestalozzi, favoreceu o processo ativo de aprendizagem que resultou na aprovação do aluno deficiente na disciplina de OO, sendo aparente a satisfação de todos os envolvidos, principalmente a do próprio aluno, que era mais apático e desmotivado ao estudo nos conteúdos da área de Programação. No entanto, se sentindo mais seguro e motivado à aprendizagem nesta área, deu ainda continuidade aos seus estudos escolhendo disciplinas do eixo da Programação no semestre seguinte, em que também alcançou êxito e conseguiu desenvolver atividades em grupo, assumindo responsabilidades junto aos seus colegas, que tinham mais segurança e confiança nele.

Dessa forma, os objetivos de inclusão social, além da própria aprendizagem de novos conhecimentos, puderam ser constatados, possibilitando a este aluno deficiente um 
VIII Congresso Brasileiro de Informática na Educação (CBIE 2019)

Anais do XXV Workshop de Informática na Escola (WIE 2019)

ambiente agradável de interação e evolução intelectual e social com apoio do tutor humano (aluno tutor) e do agente virtual (MInA).

\section{Conclusões}

O desrespeito com as diferenças geralmente fomenta mais dificuldades aqueles que mais precisam de compreensão e auxílio, descaracterizando o sentido literal da expressão "humanidade" nos seres que mais as deveriam ter ou praticar (os seres humanos).

A elaboração deste trabalho procura esclarecer que a tutoria não colaborou somente com as assimilações dos novos conhecimentos do aluno com deficiência, mas também agregou experiência de vida e conhecimento ao tutor e aos participantes desta oportunidade de estudo para a vida de cada um (turma). O aluno tutor, em especial, pôde acompanhar o esforço do aluno deficiente em superar as barreiras para uma aprendizagem adequada, colaborando, de maneira efetiva, com esse aluno e com o processo educacional como um todo. Analisando, comparativamente, na Figura 4 se constata que o tutor precisou de mais orientações que o aluno deficiente, no entanto, realizando um volume menor de questões e alcançando a sua aprovação mais segura na disciplina. Sua preocupação em estar apto para atender as dúvidas do aluno com deficiência contribuiu, de maneira salutar, com os esforços prévios de compreensão sobre os novos conteúdos da disciplina, além de lhe propiciar uma experiência de vivência mais pedagógica.

A principal contribuição deste trabalho consiste em reforçar que os métodos pedagógicos mais tradicionais precisam ser adaptados para atender aos requisitos das necessidades dos alunos com deficiência, tornando, realmente, o ambiente de aprendizagem nas instituições de ensino brasileiras, um sistema mais inclusivo e atento para as características de cada aprendiz. Tecnologias adequadas devem ser empregadas para facilitar o sucesso do processo educacional, atendendo as suas demandas pedagógicas e metodológicas de maneira mais dinâmica e condizente com as necessidades dos diferentes aprendizes e dos demais colabores desse processo (docentes, tutores, coordenadores entre outros).

Apesar do esforço do tutor ser menor para alcançar seus objetivos, ele se empenhou em auxiliar o aluno deficiente registrando 24 atendimentos no módulo Monitoria do SAE e, em somente dois desses registros, o tutor solicitou a orientação do professor de como proceder no apoio ao aluno deficiente que estava com dificuldade de assimilação.

Como foi possível observar durante o semestre letivo, a interação do aluno deficiente com o agente MInA, envolveu aspectos lúdicos e de construção de objetivos inerentes aos interesses do aprendiz. Em depoimentos espontâneos do próprio aluno em sala de aula foi possível testemunhar que existiram alguns momentos de estudo em que ele se afeiçoava mais com o agente, que o ajudava na compreensão do conteúdo. Porém, em outros momentos o aluno com deficiência estava empenhado em alcançar o sucesso que o agente lhe solicitava e ele não conseguia atingir tão facilmente. Assim, se estabelecia um "jogo" entre ambos (aluno e agente virtual), que colaborava com o processo educacional mais objetivo e ativo.

Desta forma, a combinação entre os recursos humanos e tecnológicos favoreceu a educação personalizada deste aluno com deficiência, que alcançou seu êxito com a aprovação, passando a ser mais independente nos conteúdos relacionados com a Programação Orientada a Objetos e a utilizar, com maior segurança, suas habilidades sociais, no âmbito da educação, e intelectuais em sua vida. A aprovação de ambos (aluno 
VIII Congresso Brasileiro de Informática na Educação (CBIE 2019)

Anais do XXV Workshop de Informática na Escola (WIE 2019)

deficiente e tutor) na disciplina indica o sucesso em seu processo educacional, sendo reforçado pela postura do tutor em continuar colaborando com seus colegas de turma em outras disciplinas como monitor, enquanto que o aluno com deficiência se manteve mais motivado e confiante em continuar seus estudos em Programação, adquirindo maior facilidade na interação social com os demais colegas em outras turmas/disciplinas.

\section{Referências}

Ausubel, D. P.; Novak, J. D. e Hanesian, H. (1980) Psicologia Educacional. Rio de Janeiro: Interamericana.

Azevedo, B. F. T. e Tavares, O. L. (2018) Um Sistema Tutor Inteligente para suporte à aprendizagem de "Conceitos de Orientação à Objetos", Disponível: $<$ http://www.inf.ufes.br/ tavares/sticoo.html>. Acesso: outubro.

Caetano, D. (1993) Classificação de Transtornos Mentais e de Comportamento da CID 10: Descrições Clínicas e Diretrizes Diagnosticas, Artmed.

Delgado, C.; Xexeo, J. A. M.; Souza, I. F.; Campos, M. e Rapkiewicz, C. E. (2004) Uma abordagem pedagógica para iniciação ao estudo de Algoritmos. In Workshop sobre Educação em Computação, Salvador. Anais SBC.

Gomes, M. P. C.; Ribeiro, V.M.B.; Monteiro, D.M.; Leher, E.M.T. e Louzada, R. C. R. (2010) O uso de Metodologias Ativas no ensino de graduação nas Ciências Sociais e da Saúde: avaliação dos estudantes. In Ciência\& Educação, 16 (1), 181-198.

Melo, F. R.; Flores, E. L.; Carvalho, S.D.; Martins, W.; Carrijo, G.A. e Veiga, A.C.P. (2012) Conteúdo didático multinível para personalização reativa em Sistemas Tutores Inteligentes. In Revista Controle \& Automação, 23(6), 679-693.

Moreira, M. A. (2010) Mapas Conceituais e Aprendizagem Significativa. SP: Centauro.

Omar, N.; Fonseca, I. N. e Pasotto, D. (2004) Um Sistema Especialista de Apoio à Aprendizagem da Linguagem Java. In Congresso Nacional de Ambientes Hipermídia para Aprendizagem, Florianópolis, SC.

PPNE - Programa de Apoio às Pessoas com Necessidades Especiais (2019) "Programa de Apoio às Pessoas com Necessidades Especiais", Disponível: $<$ http://www.ppne.unb.br/>. Acesso: maio.

Rissoli, V. R. V. e Santos, G. A. (2013) O Agente Pedagógico Animado MInA. In SBIE, Campinas (SP). Anais SBC. 828-837p.

Rissoli, V. R. V. e Santos, G. A. (2011) Um Assistente Inteligente Fuzzy no Acompanhamento da Aprendizagem Significativa. In CSBC, Encontro Nacional de Inteligência Artificial, Natal, RS. Anais SBC.

Santos, S. V. (2010) Educação Inclusiva: Considerações acerca do uso das tecnologias contemporâneas. In Revista Espaço Acadêmico, 10(109), 51 - 57.

Scoot, M. L. (2005) Programming Language Pragmatics, 2 ed. Morgan Kaufmann.

TightVNC Software (2019) "TightVNC", Disponível: <http://www.tightvnc.com/>. Acesso: março.

Veneziano, W. H.; Pereira, M. H. B. E.; Thomaz, L. S. S.; Moreira, T. E. G. e Meller, N. (2016) Ferramenta Educacional de Tecnologia Assistiva para o Ensino e Prática da Matemática Social de Jovens e Adultos com Deficiência Intelectual. In SBIE, Uberlândia (MG). Anais SBC. 886-895 p. 